\title{
LATTICE SITES OF SILICON IMPURITIES IN AlGaAs GROWN BY LIQUID PHASE EPITAXY*
}

\author{
P. KACZOR ${ }^{a}$, M.J. AsHWIN ${ }^{b}$, D. DoBosZ ${ }^{a}$, Z.R. ŻYTKIEWICZ ${ }^{a}$, \\ R.C. NEWMAN ${ }^{b}$ AND L. DOBACZEWSKI ${ }^{a}$ \\ ${ }^{a}$ Institute of Physics, Polish Academy of Sciences \\ Al. Lotników 32/46, 02-668 Warsaw, Poland \\ ${ }^{b}$ Interdisciplinary Research Centre for Semiconductor Materials \\ Imperial College of Science, Technology and Medicine \\ Prince Consort Road, London SW7 2BZ, United Kingdom
}

Localised vibrational mode infrared absorption (10 K) and IIall measurements were made on a series of $\mathrm{Si}$ doped $\mathrm{Al}_{x} \mathrm{Ga}_{1-x}$ As samples with $0 \leq x \leq 0.25$ grown by liquid phase epitaxy. Localised vibrational modes were detected from $\mathrm{Si}_{\mathrm{Ga}}$ donors, $\mathrm{Si}_{\mathrm{As}}$ acceptors and $\mathrm{Si}_{\mathrm{Ga}_{a}}-\mathrm{Si}_{\mathrm{As}}$ pairs which increased in frequency as $x$ increased. The assignments of new lines observed at 386,388 and $391 \mathrm{~cm}^{-1}$ are discussed in relation to possible perturbations of the lines from $\mathrm{Si}_{\mathrm{Ga}}$ or $\mathrm{Si}_{\mathrm{As}}$. The presence of $\mathrm{DX}$ centres was inferred from observed persistent photoconductivity and attempts were made to relate this result to the presence of the new IR lines.

PACS numbers: 78.30.Fs, 63.20.Pw, 61.72.-y

Silicon is the most widely used $n$-type dopant in GaAs and AlGaAs. All the essential features of its amphoteric behaviour in GaAs grown by the Bridgman, liquid encapsulated Czochralski and molecular beam epitaxy (MBE) techniques are now understood as a result of investigations using infrared (IR) localised vibrational mode (LVM) absorption spectroscopy [1]. These measurements have led to calibrations relating the integrated absorption of the various lines to the concentrations of $\mathrm{Si}_{\mathrm{Ga}}$ donors, $\mathrm{Si}_{\mathrm{As}}$ acceptors and $\mathrm{Si}_{\mathrm{Ga}}-\mathrm{Si} \mathrm{As}_{\mathrm{As}}$ donor-acceptor pairs, etc. [2]. We are aware of only one publication describing similar measurements for MBE $\mathrm{Al}_{x} \mathrm{Ga}_{1-x}$ As with $x \leq 0.2$ [3] but assignments of LVM lines are not in general available for this material grown either by MBE or liquid phase epitaxy (LPE). In addition, the microscopic mechanism of DX-centre formation remains unclear for both GaAs and AlGaAs [4]. In $\mathrm{Al}_{x} \mathrm{Ga}_{1-x} \mathrm{As}$ for alloy compositions $x>22 \%$, or in GaAs under high hydrostatic pressure, some fraction of the silicon impurities are present as DX centres [2]. The Si atom is believed to go off-centre towards an

*This work has been financially supported by the Committee for Scientific Research grant No. 2P302 11705 and the British Council-Committee for Scientific Research grant No. WAR/992/065. 
interstitial position and thereby breaks one of the original nearest neighbour $\mathrm{Si}-\mathrm{As}$ bonds [5]. This state is stabilised when the ionised Si donor captures two electrons (negative- $U$ system). There is much experimental evidence to support this view [4], although there is still no consensus concerning the magnitude of the lattice relaxation. LVM absorption spectroscopy is a direct method which can be used to determine the lattice sites of the Si-impurity in both the relaxed (deep DX-state) and unrelaxed (shallow hydrogenic state) states. Only one such absorption experiment has been carried out [6] on GaAs while it was subjected to a high hydrostatic pressure but there is still discussion about the interpretation of the results [1]. A clarification might ensue from studies of AlGaAs:Si for which the application of high pressure is not required for the formation of DX centres. The purpose of this paper is to report LVM measurements for a series of LPE Si doped $\mathrm{Al}_{x} \mathrm{Ga}_{1-x} \mathrm{As}$ samples with values of $0 \leq x \leq 0.25$.

The samples were grown by LPE at a temperature $T=900^{\circ} \mathrm{C}$ to a thickness of $3-5 \mu \mathrm{m}$ with $x$ in the range 0 to 0.25 . The samples with low Al contents $\left(x_{\mathrm{Al}}<0.05\right)$ grown from melts containing $7 \mathrm{~mol} \%$ of Si were $p$-type and were highly compensated. Samples with higher Al contents $\left(x_{\mathrm{Al}}>0.1\right)$ grown from melts containing a lower amount of silicon $\left(x_{\mathrm{Si}}=5 \mathrm{~mol} \%\right)$ were all $n$-type with free carrier concentrations ranging from $1.0 \times 10^{17}$ to $1.0 \times 10^{18} \mathrm{~cm}^{-3}$. Persistent photoconductivity (PPC), characteristic of the DX centres [4], was observed from samples with $x>22 \%$ by both Hall-effect and IR-absorption measurements. Fourier transform IR-spectra were obtained with a Bruker IFS120HR interferometer at a resolution of $0.25 \mathrm{~cm}^{-1}$ and with the samples at $T \approx 10 \mathrm{~K}[1]$.

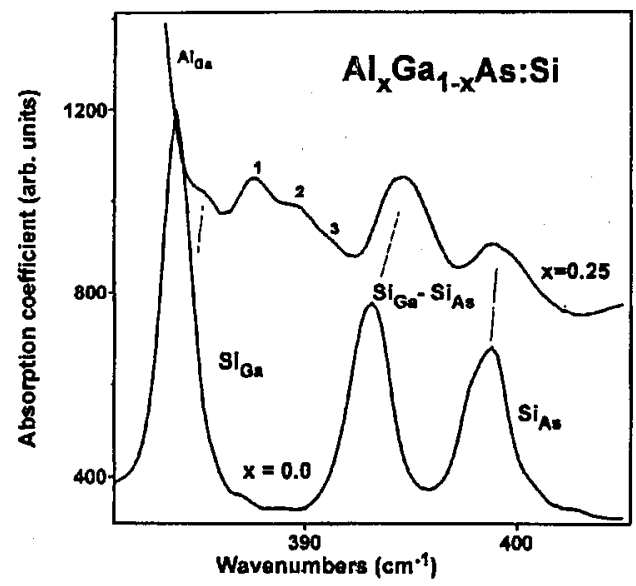

Fig. 1. An absorption spectrum of LPE $\mathrm{Al}_{x} \mathrm{Ga}_{1-x} \mathrm{As}(x=0.25)$ together with a corresponding spectrum for GaAs. The LVMs due to $\mathrm{Si}_{\mathrm{Ga}}\left(384 \mathrm{~cm}^{-1}\right), \mathrm{Si}_{\mathrm{Ga}}-\mathrm{Si}_{\mathrm{As}}\left(394 \mathrm{~cm}^{-1}\right)$ and $\mathrm{Si}_{\text {As }}\left(399 \mathrm{~cm}^{-1}\right)$ in $\mathrm{GaAs}$ shift to higher frequencies as the aluminium content is increased. The $\mathrm{Si}_{\mathrm{Ga}}$ mode decreases in strength and three new lines labelled 1-3 appear at 386,388 and $391 \mathrm{~cm}^{-1}$ (see text). 
IR absorption lines from $\mathrm{Si}_{\mathrm{Ga}}, \mathrm{Si}_{\mathrm{As}}$ and $\mathrm{Si}_{\mathrm{Ga}}-\mathrm{Si}_{\mathrm{As}}$ pairs were observed in the various samples except that from $\mathrm{Si}_{\mathrm{Ga}}$ in the material with the highest values of $x$ (Fig. 1). The concentration of each species was estimated for the GaAs sample using calibration factors (each with a quoted accuracy no greater than $\pm 10 \%$ ) [7], leading to $\left[\mathrm{Si}_{\mathrm{Ga}}\right]=1 \times 10^{20} \mathrm{~cm}^{-3},\left[\mathrm{Si}_{\mathrm{As}}=8 \times 10^{19} \mathrm{~cm}^{-3}\right.$. In principle, the difference $\left(\left[\mathrm{Si}_{\mathrm{Ga}}\right]-\left[\mathrm{Si}_{\mathrm{As}}\right]\right)$ yields the net free carrier concentration, assuming that there are no other donors, acceptors or deep traps present. According to this procedure, the crystal is expected to be $n$-type with $n \approx 2 \times 10^{19} \mathrm{~cm}^{-3}$ but since we take the difference between two large quantities the accuracy is limited, explaining the apparent disagreement with the Hall data which indicates that the sample is $p$-type with $p \approx 2 \times 10^{15} \mathrm{~cm}^{-3}$.

As the Al-content was increased from $x=0$ up to $x=0.25$, all the Si-related $\mathrm{Si}_{\mathrm{Ga}}, \mathrm{Si}_{\mathrm{As}}$ and $\mathrm{Si}_{\mathrm{Ga}}-\mathrm{Si}_{\mathrm{As}}$ pairs LVMs shifted monotonically to higher frequencies by $1.5 \mathrm{~cm}^{-1}$, except for the $\mathrm{Si}_{\mathrm{As}} \mathrm{LVM}$. Any changes in the full width at half maximum $(\Delta)$ of the lines were less than $10 \%$ of the initial line widths, which were $\approx 2.6 \mathrm{~cm}^{-1}$ for the $\mathrm{Si}_{\mathrm{As}}$ and $\mathrm{Si}_{\mathrm{Ga}}-\mathrm{Si}_{\mathrm{As}} \mathrm{LVMs}$ and $\approx 2 \mathrm{~cm}^{-1}$ for the $\mathrm{Si}_{\mathrm{Ga}}$ mode: the large values of $\Delta$ result from the high impurity concentration. As the $\mathrm{Al}$ concentrations increased, there was a progressive appearance of three new lines on the high frequency side of the $\mathrm{Si}_{\mathrm{Ga}}$ LVM (Fig. 1). A line at $386 \mathrm{~cm}^{-1}$ was observed for $x \geq 0.03$, the second at $388 \mathrm{~cm}^{-1}$ for $x \geq 0.1$ and the third at $391 \mathrm{~cm}^{-1}$ for $x \geq 0.25$. The $384 \mathrm{~cm}^{-1}$ line $\left(\mathrm{Si}_{\mathrm{Ga}}\right)$ became weaker with respect to the new lines and was not detectable for $x \geq 0.25$. The $\mathrm{Si}_{\mathrm{Ga}}-\mathrm{Si}_{\mathrm{As}} \mathrm{LVM}$ at $393 \mathrm{~cm}^{-1}$ exhibited no broadening or "splitting" while the $\mathrm{Si}_{\mathrm{As}} \mathrm{LVM}$ at $399 \mathrm{~cm}^{-1}$ showed only a small shoulder at a higher energy of $\approx 400 \mathrm{~cm}^{-1}$ for $x \geq 0.14$.

For $x=0.22$ and $x=0.25$ a substantial freeze-out of free carriers $(n)$ was observed by both IR-absorption and Hall measurements when the sample was cooled in darkness: at $T \leq 77 \mathrm{~K}$ the $n$ (Hall) was reduced by an order of magnitude from its value at room temperature $\left(2 \times 10^{17} \mathrm{~cm}^{-3}\right)$. Subsequent illumination of the samples while they were maintained at a low temperature resulted in an increase in $n$ and there was no reduction when the illumination was removed. This persistent photoconductivity implies that the free carriers (electrons) were trapped by DX-levels. Nevertheless, expected correlated changes of the Si lattice sites were not observed in IR spectra. That is, no new LVMs were produced and there were no changes in the strengths of the lines observed prior to the illumination.

If the vibrational mode of $\mathrm{Si}(\mathrm{DX})$ in GaAs were at $376 \mathrm{~cm}^{-1}$ (extrapolated frequency for zero pressure) [6], the line would not be observable for values of $x>0.22$ because of the overlapping absorption from the "AlAs"-like reststrahl (see Fig. 1). It might then be argued that the formation of DX centres explains the decrease in the strength of the $\mathrm{Si}_{\mathrm{Ga}}$ line as the Al concentration was increased. Nevertheless, the presence of one or more perturbed shallow donor lines should still be expected in illuminated samples. Since all the $\mathrm{Si}_{\mathrm{Ga}}$ atoms would have four As nearest neighbours and vibrational amplitudes associated with LVMs normally involve only the impurity and its nearest neighbours [8], any changes in their vibrational frequencies would be small. A second possibility is that lines labelled 1-3 are due to Si atoms located in DX configurations with second nearest neighbours interactions with $\mathrm{Al}$ atoms. However, it is then difficult to understand why 
changes in the strength of these lines were not observed when the samples were illuminated at low temperature. Alternatively, the new modes 1-3 may be due to $\mathrm{Si}_{\mathrm{As}}$ modes modified by the presence of one or more $\mathrm{Al}$ nearest neighbours. This would produce centres with $C_{3 v}\left(2\right.$ modes) and $C_{2 v}$ ( 3 modes) etc. leading to the removal of the threefold degeneracy of the original LVM. Additional modes could be obscured by other lines due to $\mathrm{Si}_{\mathrm{Ga}}-\mathrm{Si}_{\mathrm{As}}$ pairs and/or $\mathrm{Si}_{\mathrm{As}}$. The weak feature at $400 \mathrm{~cm}^{-1}$ could be due to one of these modes. Although new lines have been found in this study of AlGaAs grown by LPE, further work is required before a definitive interpretation can be proposed.

\section{References}

[1] R.C. Newman, Semicond. Sci. Technol. 9, 1749 (1994).

[2] For a review see R.C. Newman, in: Semiconductors and Semimetals, Vol. 38, Eds. R.K. Willardson, A.C. Beer, vol. ed. E.R. Weber, Academic Press, New York 1993, p. 115.

[3] R. Murray, R.C. Newman, P.S. Nandhra, R.B. Beall, J.J. Harris, P.J. Wright, Mater. Res. Soc. Symp. Proc. 104, 543 (1988).

[4] For a review see K.J. Malloy, K. Khachaturian, in: Serniconductors and Semimetals, Vol. 38, Eds. R.K. Willardson, A.C. Beer, vol. ed. E.R. Weber, Academic Press, New York 1993, p. 235.

[5] D.J. Chadi, K.J. Chang, Phys. Rev. Lett. 61, 873 (1988); Phys. Rev. B 39, 10063 (1989).

[6] J.A. Wolk, M.B. Kruger, J.N. Heyman, W. Walukiewicz, R. Jeanloz, E.E. Haller, Phys. Rev. Lett. 66, 774 (1991).

[7] M.J. Ashwin, M.R. Fahy, R.C. Newman, J. Wagner, D.A. Robbie, M.J.L. Sangster, I. Silier, E. Bauser, W. Braun, K. Ploog, J. Appl. Phys. 76, 7839 (1994).

[8] M.J.L. Sangster, R.C. Newman, G.A. Gledhill, S.B. Upadhyay, Semicond. Sci. Technol. 7, 1295 (1992). 